Ernani Cesar de

Freitas

Doutor em letras

(PUCRS), com pós-Doutorado em Linguística Aplicada e Estudos da Linguagem (PUC-SP/ LAEL).

Docente do PPG em Processos e Manifestações Culturais na Universidade Feevale.

Lattes; http://

lattes. cnpq.

br/9653110286244674

Gislene Feiten Haubrich

Doutoranda e mestre em Processos e Manifestações Culturais pela Universidade Feevale. Lattes: http://lattes.cnpq. br/9771390371218321

\section{Prescrições e interações: como 0 trabalho media a produção de sentidos?}

Prescriptions and interactions: How the labor mediates the production of meanings?

Prescripciones y interacciones: como el trabajo media la producción de sentido? 
Resumo

Este estudo pressupõe o trabalho como prática sociocultural mediadora da socialização de saberes entre os sujeitos. Entende, ainda, o trabalhador como protagonista na mobilização da cultura organizacional ante as transgressões e renormalizações em situação. Este artigo visa compreender como os processos interacionais da atividade podem ser implicados pelos sentidos construídos por editoriais de jornal de empresa. Três categorias são articuladas para a fundamentação do estudo: processos interacionais nas organizações (OLIVEIRA; PAULA, 2008), concepções ergológicas da atividade (SCHWARTZ; DURRIVE, 2007; TRINQUET, 2010) e a análise semiolinguística do discurso (CHARAUDEAU, 2010, 2012). A pesquisa é um estudo de caso realizado na empresa de automação industrial Hera, localizada no Parque Tecnológico do Vale dos Sinos, no Rio Grande do Sul. A composição do corpus é efetivada por oito editoriais do jornal da empresa, divulgados no período de janeiro de 2012 a junho de 2014. A estratégia de análise é denominada teórico-ergo-discursiva. Dentre os resultados da pesquisa, assume evidência a consistência empírica da materialidade selecionada na investigação. Como gênero discursivo permeado por intencionalidades acerca do exercício da ação profissional, os editoriais permitem a identificação de implicações como: neutralidade atribuída ao fazer dos sujeitos, enquadramento das práticas laborais às normas da cadeia produtiva, que prejudica, por exemplo, a inovação na produção de produtos e serviços, além de suprimir o aprimoramento pessoal e criativo dos trabalhadores.

Palavras-chave: interação; linguagem; atividade laboral; editoriais; cultura.

\section{ABSTRACT}

This study presupposes work as a socio-cultural practice mediating the socialization of knowledge among the subjects. It also understands the worker as a protagonist in the mobilization of the organizational culture in face of the transgressions and renormalizations in place. This paper aims at understanding how the activity's interactive processes can be affected by the senses built by business newspaper editorials. The study is based on three categories: the interaction processes within organizations (OLIVEIRA, PAULA, 2008), the activity's ergological conceptions (SCHWARTZ, DURRIVE, 2007, TRINQUET, 2010), and the semiolinguistic discourse analysis (CHARAUDEAU, 2010, 2012). The research is a case study carried out in Hera, an industrial automation company located in the Technological Park of Vale dos Sinos, in Rio Grande do Sul. The study's framework is built by eight editorials of the company's newspaper, published from January 2012 to June 2014. This is called a theoretical-ergo-discursive analysis. Among all the study's results, the empirical consistency of the selected materiality gains evidence. As a discursive genre permeated by intentionalities about the professional action, the editorials allow the identification of implications such as: the neutrality attributed to the subjects' action, the framing of labor practices according to the production chain's norms, which harms, for example, the innovation in the production of products and services, as well as suppresses the workers' personal and creative improvement.

Keywords: interaction; language; work activity; editorials; culture.

\section{RESUMEN}

El estudio presupone el trabajo como práctica sociocultural mediando la socialización del conocimiento entre los sujetos. También entiende al trabajador como protagonista en la movilización de la cultura organizacional frente a las transgresiones y renormalizaciones en curso. Este trabajo tiene como objetivo comprender cómo los procesos interactivos de la actividad pueden verse afectados por los sentidos construidos por editoriales de periódicos empresariales. El estudio se basa en tres categorías: los procesos de interacción dentro de las organizaciones (OLIVEIRA, PAULA, 2008), las concepciones ergológicas de la actividad (SCHWARTZ, DURRIVE, 2007, TRINQUET, 2010) y el análisis semiolingüístico del discurso (CHARAUDEAU, 2010, 2012). La investigación es un estudio de caso realizado en Hera, una empresa de automatización industrial ubicada en el Parque Tecnológico de Vale dos Sinos, en Rio Grande do Sul. El corpus del estudio está construido por ocho editoriales del periódico de la compañía, publicados entre enero de 2012 y junio de 2014. La estrategia de análisis se llama teórico-ergo-discursiva. Entre todos los resultados del estudio, la consistencia empírica de la materialidad gana evidencia. Como un género discursivo impregnado de intenciones sobre la acción profesional, los editoriales permiten identificar implicaciones como: la neutralidad atribuida a la acción de los sujetos, la adecuación de prácticas laborales según las normas de la cadena productiva, lo que perjudica, por ejemplo, la innovación en la producción de productos y servicios, así como suprime la mejora personal y creativa de los trabajadores. Palabras-clave: interacción; lenguaje; actividad laboral; editoriales; cultura

Submissão: 21-1-2016

Decisão editorial: 8-3-2017 


\section{Considerações iniciais}

O trabalho pode ser compreendido sob olhares múltiplos. Condicionamentos tradicionais evidenciam seu uso como mecanismo para manutenção do sistema capitalista ou estrutura de exploração dos sujeitos. Perspectivas ressignificadas, na contramão, o apreendem como prática sociocultural, instância de socialização de saberes e espaço de microgestões realizadas pelo trabalhador. Independentemente do ponto de vista adotado, fato inegável é que o trabaIho refere-se a um elemento ordenador social e instituidor das relações sociais. Com base nesse aspecto e ante a diversidade que historicamente constrói a noção de trabalho, aos pesquisadores é fundamental uma escolha. Desse modo, este estudo defende que a atividade laboral mobiliza sentidos e estabelece significados no espaço organizacional, movimentando, assim, a cultura e a sociedade na qual se desenvolve.

A breve contextualização apresentada e a inscrição aos pressupostos de investigação da semiolinguística discursiva e da ergologia permitem o delineamento das questões norteadoras da pesquisa: os editoriais do jornal da empresa Hera podem implicar os processos interacionais da atividade profissional mediante um fazer linguageiro-comunicativo estruturado por visadas de informação (fazer-saber) 
e captação (fazer-sentir)? O uso dessas estratégias discursivas em consonância com o contrato e a situação de comunicação é permeado pela intenção de neutralizar a ação renormalizadora dos sujeitos no trabalho? Diante desses pontos, o objetivo dos autores neste trabalho é compreender como os processos interacionais da atividade laboral podem ser implicados pelos sentidos construídos nos enunciados verbais de editoriais de jornal de empresa.

O corpus da pesquisa é composto por oito editoriais do jornal da empresa Hera, atuante na indústria de automação e localizada na região do Vale dos Sinos (RS/BR). A divulgação dos discursos em análise compreende o período de janeiro de 2012 a junho de 2014, totalizando sete edições do periódico. O estudo de caso é desenvolvido com base na análise teórico-ergo-discursiva, com interface entre concepções teóricas e o objeto empírico. A estrutura do artigo é dividida em três partes, a começar pela fundamentação teórica sobre a atividade profissional laboral e seus processos interacionais. Na sequência, delineia-se brevemente a construção metodológica que estrutura a análise, etapa que encaminha às considerações finais.

\section{O discurso prescritivo e a produção de sentidos}

Ao longo do tempo, os estudos enunciativos têm se desenvolvido e alcançado relevância para o entendimento das experiências humanas, visto que por meio da linguagem os sujeitos experimentam o mundo. Ao tratar da noção de intersubjetividade, ou a capacidade de estabelecer consciência de si, Benveniste (2008, p. 286) afirma que é "na linguagem e pela linguagem que o homem se constitui como sujeito; porque só a linguagem fundamenta na realidade, na sua realida- 
de que é a do ser". Estão implicados aí, por um lado, os sujeitos do ato linguageiro: reconhecer a si como locutor de um enunciado e atribuir ao outro a função de interlocutor. Por outro lado, o quadro social e ideológico agregado e desbravado por Bakhtin/Volochínov (2014, p. 127) faz saber da relevância das interações verbais como "fenômeno social [...] realizado através da enunciação ou das enunciações" basilares à constituição do Outro e do Eu.

A proposição da teoria semiolinguística do discurso de Charaudeau $(2010,2012)$ ancora-se e desenvolve-se no diálogo entre as duas perspectivas. Explicita a atuação das posições de pessoa benvenistianas, ao mesmo tempo em que agrega aspectos contextuais, situacionais e dialógicos do ponto de vista bakhtiniano. A proposta de Charaudeau "considera o ato de comunicação como um 'jogo', ou seja, o ato de comunicação se mantém em uma constante manobra de equilíbrio e de ajustamento entre as normas (restrições) de um dado discurso e a margem de manobras permitida pelo mesmo discurso" (PAULIUKONIS; GOUVÊA, 2012, p. 58, grifo do autor). Nesse sentido, quatro são os sujeitos envolvidos pelo ato de linguagem: dois seres sociais, o sujeito comunicante (EUC) e o sujeito interpretante (TUi), e dois seres de fala, o sujeito enunciador (EUe) e o sujeito destinatário (TUd).

A encenação discursiva (mise-en-scène) dá-se na relação entre EUe e TUd. O enunciador (EUe) é responsável por articular interesses e implicações contextuais/situacionais que permeiam sua relação com o TU. Ao idealizar um percurso, o EU aspira à figura do interpretante (TUi), que assume a posição de destinatário ideal (TUd), aquele que pode ser persuadido à intencionalidade do EUc, projetada e configurada 
pelo EUe. Charaudeau (2010, p. 63) salienta que o sujeito analisador, inicialmente externo a essa configuração de papéis discursivos, "deve, sim, dar conta dos possíveis interpretativos". Enquanto o EUc explicita o dito, ao analista do discurso é dada a oportunidade de explorar a relação entre EUe e TUd e identificar estratégias discursivas utilizadas. Essas questões são relevantes ao interesse desta pesquisa, cujo ímpeto está no diagnóstico de possíveis implicações dos discursos organizacionais aos processos interacionais da atividade profissional.

Da dinâmica de ação desses sujeitos, percebe-se que ao descrever uma situação o EU busca, em seu repertório, signos que possam representá-la. Essa busca não é ingênua, mas depende da finalidade que possui. Charaudeau (2012) denomina essas escolhas discursivas "visadas comunicativas" e as classifica ante a relação que o EU visa estabelecer com o TU. Quatro são as principais visadas: a) "prescrição" e a relação entre fazer-saber e dever-saber; b) "incitação", cuja relação se dá entre mandar-fazer e dever-acreditar; c) "informação", na qual ao EU cabe fazer-saber e ao TU, dever-saber; d) "captação" que transita entre o fazer-sentir e o dever-sentir. O EUc toma a palavra e propaga a mensagem elaborada pelo EUe e, nesse sentido, a visada passa a ser uma síntese entre a intencionalidade do EU e a atitude esperada do TUd. Não há, porém, controle algum, por parte do EUc, de que esse envolvimento ocorra quando o TUi interagir com os enunciados proferidos.

Percebe-se que a construção de um discurso é um ato estratégico, ancorado em quatro diferentes modos de organização dos enunciados, que apoiam o EU na sedução do TU. Enunciativo, descritivo, narra- 
tivo e argumentativo são os quatro modos esclarecidos por Charaudeau (2010) para compreender a concretização de enunciados e a produção de sentidos. O modo de organização enunciativo "aponta a maneira pela qual o sujeito falante age na encenação" (CHARAUDEAU, 2010, p. 81). Seja por meio de uma relação de influência ou de força (função alocutiva), da expressão de um ponto de vista (função elocutiva) ou do uso de uma terceira pessoa para subsidiar seus argumentos (função delocutiva), o EUe define bem qual é sua posição em relação ao seu interlocutor. $O$ modo de organização descritivo constitui-se da nomeação, localização e qualificação do objeto de fala, cujo foco está na produção de efeitos de verdade. Já o modo narrativo subsidia o encadeamento de ações, enquanto o modo argumentativo tem como função "construir explicações sobre asserções feitas do mundo" (CHARAUDEAU, 2010, p. 207).

Salienta-se que esse uso linguageiro só se torna estratégico, pois está em inter-relação com o contexto que possibilita a distribuição dos papéis aos atores sociais. A semiolinguística charaudeana aborda essa conexão embasada no duplo processo de semiotização que transforma o "mundo a significar" (processo de transformação) em "mundo significado", ou seja, passível de propagação aos interlocutores (processo de transação). Investido à análise dos eventos cotidianos, reconhece-se a complexidade e a singularidade neles imbricados. Aqueles processos são coordenados pela ação dos sujeitos, cuja atividade decorre do reconhecimento de contrato de comunicação e das condições que mobilizam e permeiam a situação de encontro entre os atores sociais. A situação implica o quadro referencial que delimita a encenação de 
cada troca comunicacional e manifesta-se diante do estabelecimento de normas e convenções aos comportamentos linguageiros. Por sua vez, o contrato de comunicação imbrica elementos prescritos e simbólicos e estrutura-se por dados internos e externos. Os dados internos implicam a formação discursiva em si e aos três espaços de locução que compõem a construção do dito pelo EUe: a) locução (tomada da fala), b) relação (estratégias de abordagem) e c) tematização (assunto). Os dados externos advêm do campo da prática social, diante dos dados semiotizados que já orbitam no contexto.

A opção pela semiolinguística discursiva desenvolvida por Charaudeau $(2010,2012)$ evidencia o aspecto interacional das trocas linguageiras que se pretende construir neste estudo. Com base nas estratégias adotadas pelo sujeito enunciador (EUe), centra-se o olhar em possíveis produções de sentidos emergentes das interpretações do dito. Essa reflexão, no contexto da atividade, é uma alternativa à compreensão do mundo do trabalho perante o reconhecimento de factíveis expressões de protagonismo desempenhadas pelos trabalhadores (corpo-si) no âmbito organizacional. Prossegue-se, então, com a reflexão acerca da noção de trabalho e seus desdobramentos quanto às interações cotidianas.

Interações, linguagem e atividade

Esta investigação pressupõe o trabalho como prática sociocultural mediadora da socialização de saberes dos sujeitos. Entende o trabalhador como protagonista na mobilização da cultura organizacional, perante transgressões e renormalizações produzidas em situação. Esses pressupostos esclarecem que o 
trabalho não é aqui apreendido como mera execução de tarefas e normas. Assim, o trabalhador não é um assujeitado que somente se enquadra em parâmetros, tampouco atua repetitivamente tal qual engrenagem do sistema produtivo. Assume-se que ele seja autor de suas escolhas, que segue, ou não, orientações declaradas pela organização. O sujeito trabalhador é dotado de subjetividade e capacidade de experimentar o mundo (semiotização oriunda da inter-relação dos processos de transformação e de transação para Charaudeau). Entende-se que sua inteligência não pode ser enquadrada em parâmetros específicos (por vezes reducionistas) definidos por uns em detrimento dos outros.

Esse sujeito é chamado por Schwartz (2014) de corpo-si (corps-soi), um ser que promove a ação conjunta entre material e imaterial. "Seria possível compreender o corpo-si como um todo em confronto 'ativo' com um meio ecológico-social" (SCHWARTZ, 2014, p. 265). À luz dessas considerações, emerge uma atualização da noção de trabalho. O ponto de vista ergológico parte da noção de atividade humana do trabalho que está na "esfera das múltiplas microgestões inteligentes da situação" (SCHWARTZ, 2004, p. 37). Para Trinquet (2010, p. 96), a atividade é o "debate de normas e de transgressões, o que, frequentemente, resulta em renormalizações". Como entender tal debate senão pelo percurso das interações linguageiras e/ou comunicativas?

O conceito angular da ergologia tem origem na distância entre o prescrito e o real. Nesse caso, o normalizado (prescrito) é constantemente transgredido (real), visto que a subjetividade da interpretação da norma garante unicidade na resposta ao posto. Assim, 
o trabalho, entendido como atividade, é percebido como um processo de apropriação comunicacional e de articulação de sentidos que culminam em manifestações linguageiras ou discursivas que interconectam sujeitos e situações. Para tanto, o enfoque material do trabalho, com base na 'coisa' produzida', concede espaço à posição ativa do trabalhador, que por meio de sua atividade constrói a realidade na articulação de sentidos e saberes.

A esse movimento transgressor Schwartz (2014) denomina dramáticas dos usos de si. O sujeito, no trabalho, faz uso "de suas próprias capacidades, de seus próprios recursos e de suas próprias escolhas" (SCHWARTZ; DURRIVE, 2007, p. 192). Fazer uso de si representa trazer as experiências de vida para as escoIhas do trabalho, que permitem ao sujeito (re)criar-se e (re)criar a realidade. Schwartz (2014) utiliza o termo dramática, pois em sua concepção as problemáticas cotidianas da atividade articulam-se umas às outras como um drama em situações não previstas. Duas são as dramáticas aí envolvidas: o uso de si pelo outro, expresso por normas e prescrições postas e o uso de si por si, que implica a autogestão, as escolhas em situação real.

Vinculadas aos usos de si estão outras duas dimensões fundamentais do trabalho: as normas, o uso de si pelo outro, a prescrição, a ação planejada da comunicação e as renormalizações, o uso de si por si, a interação do sujeito com seus saberes, com suas experiências e com o outro. Essas duas faces do trabalho implicam o trânsito de saberes constituídos

Relaciona-se à crítica marxista centrada na noção de que o homem e seu trabalho são, no modo de vida capitalista, meras mercadorias. Para aprofundamento, sugere-se a leitura dos Manuscritos Econômico-Filosóficos, de Marx. 
pela organização, cuja manifestação está formalizada em documentos como manuais, relatórios etc. e investidos pelo sujeito, que evoca seu conhecimento tácito, da experiência e culmina com a produção de novos saberes e sentidos, renormalizados. "Os saberes produzidos antecipam a atividade e, ao mesmo tempo, a atividade antecipa saberes que ainda não foram produzidos. E essa dialética, de certo modo não tem fim [...] renova o estoque de saberes existentes" (SCHWARTZ; DURRIVE, 2007, p. 149).

Schwartz e Durrive (2007, p. 140) afirmam que "é preciso manipular conceitos. Se não, a pessoa permanece em seu horizonte que, sem dúvida, é permanentemente microcriador, mas não atua para transformar um certo [sic] número de dimensões desse horizonte". Não é possível realizar a atividade sem os saberes constituídos, que servem como guia para que se alcance um fim específico. De todo modo, é preciso considerar que a apreensão dos conceitos (ou saberes constituídos) é singular, pois o sujeito o é; e, nesse caso, não se podem desconsiderar os saberes investidos que culminam uma gestão do uso de si em situações específicas.

Conforme a articulação apresentada acerca das noções de prescrito e real, normas e renormalizações, saberes constituídos e investidos, percebe-se que a possibilidade de investimento da subjetividade humana é fundamental para o exercício dialético da criação no trabalho, expresso nas decisões tomadas pelos sujeitos em situação. Souza-e-Silva salienta que a produção de saberes emerge das experiências compartilhadas coletivamente, às quais se estruturam na/pela linguagem: "a atividade de linguagem e a atividade de trabalho estão estreitamente liga- 
das, ambas transformam o meio social e permitem as trocas e negociação entre os seres humanos" (2002, p. 61). Por meio da linguagem, a atividade é enquadrada e torna possível a reconfiguração de diferentes sentidos. A linguagem institui a relação EU $<>T U$, que é permanentemente reconstruída mediante a produção de enunciados. Como se pode supor, não é uma simples dimensão humana, mas o oposto, um complexo elemento que constitui o ser.

Estabelece-se, assim, outro cenário analítico para perceber como ocorre o trabalho. A ênfase está na ação linguageira e nas implicações comunicacionais produzidas pelos sujeitos na estruturação de práticas socioculturais e de socialização de saberes. Aceitase que, para além das prescrições, saberes de outros espaços estão inseridos no ambiente laboral e determinam experiências e aprendizado. Saraiva e Carrieri (2010, p. 213) contribuem com essa projeção e, sob o ponto de vista dos elementos simbólicos, afirmam: "[...] ainda que haja uma intencionalidade por parte da administração de uma organização ao implementar uma dada ação gerencial [...] isso não significa que os empregados se acomodarão, submissos e apáticos ao que Ihes for apresentado".

Daft e Weick (1984, p. 293), na direção do desenvolvimento de um modelo organizacional como sistema de interpretação, defendem que "para sobreviver, as organizações necessitam de mecanismos para interpretar eventos ambíguos e para prover sentidos e orientações aos seus participantes. As organizações são sistemas de significados". A elaboração de mecanismos que conduzem a interpretação dos sujeitos às interações realizadas é atribuída às lideranças e os demais sujeitos do ambiente orga- 
nizacional são eximidos desse processo. Ao passo que se aceita a produção de sentidos como evento importante à constituição da própria organização, tenta-se modalizá-los em categorias que podem ser controladas e geridas.

Acerca da produção de sentidos nas organizações dizem Oliveira e Paula (2008, p. 101): "O sentido existe na interação estabelecida e as organizações são concebidas como agentes discursivos e comunicativos, nos processos interativos que se dão dentro e fora do seu ambiente". Assim, ao considerar a proposta de estudo desta investigação, compreende-se que a constituição discursiva dos editoriais de jornal de empresa não é ingênua, mas congrega saberes constituídos, cuja articulação linguageira é utilizada para persuadir o interlocutor, que, ao interagir com o texto, investirá sua subjetividade na interpretação do dito e conduzirá novas propagações discursivas inspirado por esses ditos. Vistas sob essa perspectiva, as normas expressas pela organização em editoriais medeiam a experiência que o sujeito passa a ter com o mundo.

\section{Percursos do caminho analítico}

Esta é uma pesquisa de natureza aplicada, de cunho descritivo, com abordagem qualitativa e método de estudo de caso. Os procedimentos técnicos utilizados são as pesquisas bibliográfica e documental. A natureza dos dados que compõem a pesquisa documental os define como fontes em primeira mão, visto que ainda não receberam tratamento analítico. Conforme a delimitação do objeto, em termos documentais, o acesso aos dados provém dos editoriais dos jornais da empresa em estudo. A organização dos 
dados em estado bruto 2 foi orientada pela técnica Mapa de Associação de Ideias. O corpus é composto por oito editoriais do jornal da empresa, publicados no período de janeiro de 2012 a julho de 2014, num total de sete edições (77 a 83).

A escolha dos editoriais pautou-se por dois aspectos: 1) a avaliação do periódico como um todo, composto por matérias de cunho técnico, tornaria a análise dispersa; 2) a gênese da noção de editoriais como representação da opinião da empresa, o que evidencia aspectos interacionais do cotidiano laboral. Desse modo, mostra-se como uma fonte eficaz para compreender as possíveis implicações produzidas aos processos interacionais da atividade, pois, por meio do manifesto pelo EUc, pode-se identificar a intencionalidade do enunciador (EUe) quanto ao destinatário por ele idealizado (TUd), além de levantar possíveis interpretativos acerca da percepção que o interlocutor TUi investirá acerca do dito.

\section{Discursos, sentidos e orientações à ação pro- fissional na atividade}

Delineado o corpus e especificados os procedimentos de análise com base nas categorias teórico-ergo-discursivas, conduz-se a reflexão acerca das possíveis implicações dos enunciados que compõem os editoriais do jornal da empresa Hera aos processos interacionais da atividade. A teoria semiolinguística de análise discursiva (CHARAUDEAU, 2010, 2012) sUstenta a investigação. A caracterização da situação de comunicação selecionada e das circunstâncias

\footnotetext{
2 As tabelas com a qualificação dos enunciados, bem como os editoriais na íntegra, podem ser consultadas em: <http://biblioteca. feevale.br/Dissertacao/DissertacaoGisleneHaubrich.pdf>.
} 
que a cercam é o ponto de partida dessa etapa do artigo. Assim, dentre as múltiplas possibilidades para se estudar o trabalho, seleciona-se o jornal da empresa e, mais especificamente, alguns excertos verbais dos editoriais que fazem parte do corpus de análise. Trata-se de um periódico com divulgação quadrimestral, cuja distribuição é destinada a funcionários, fornecedores e clientes.

A opção por manter uma ferramenta difundida entre públicos diversos, expressa a perspectiva linear outorgada, pela Hera, ao processo interacional do e no trabalho. Essa organização entende que a força das informações é detida por ela, sendo os interlocutores considerados passivos ao que recebem. O acesso dos funcionários ao jornal dá-se diante do interesse do trabalhador, pois ele é disposto junto aos acessos principais da empresa. Uma versão on-line pode ser consultada no site da empresa, o que limita o acesso, em horário de expediente, apenas aos trabalhadores que têm acesso a computadores. Quanto aos locais de fala dos atores do ato de linguagem, elucida-se: EUc, Hera, uma empresa de automação industrial com matriz localizada na região metropolitana de Porto Alegre (RS); TUi, classe trabaIhadora composta por 440 funcionários 3 , 319 homens e 121 mulheres, cuja alocação é distribuída em seis diferentes estados brasileiros ${ }^{4}$. A estrutura organizacional é dividida em três grandes áreas: P\&D, engenharia e fábrica. Os autores da pesquisa assumem o papel do sujeito analisador.

3 Dados de 4 de setembro de 2014.

4 Sede em São Leopoldo (RS), a fábrica de painéis em Sapucaia do Sul (RS) e as filiais em São Paulo (SP), Campinas (SP), Macaé (RJ), Belo Horizonte (MG), Salvador (BA), Curitiba (PR) e Porto Alegre (RS). 
Reconhece-se que a condição de enunciação selecionada para o estudo, os editoriais, oportuniza à organização apresentar seus saberes e orientações. Porém, a estruturação linguageira por ela adotada nesses textos não suscita oportunidades para diálogo ou mesmo a possibilidade de escuta dos profissionais. Conforme a nota de expediente divulgada na contracapa do jornal, depreende-se que a instância de produção é múltipla, visto que o jornal é um canal produzido por uma equipe composta por sete pessoas, que revisam e determinam quais são os temas e as formas de abordagem para cada edição. Embora os editoriais sejam assinados, algumas nuanças na forma de construção dos enunciados conduzem à percepção de que não são escritos por uma pessoa, o presidente, mas que são textos revisados e reenquadrados nos parâmetros definidos como adequados à interação que se pretende com o público leitor.

Justifica-se tal apontamento tendo em conta a construção discursiva (CHARAUDEAU, 2010) dos editoriais. O excerto "a história da Hera demonstra que desenvolvemos as bases necessárias para novas conquistas: profissionais qualificados, produtos de classe mundial, soluções tecnológicas e inovadoras e excelência em gestão" exemplifica a ancoragem nos modos enunciativo e descritivo proeminentes na Edição 77, além da identificação dos assuntos abordados naquela situação com base na função elocutiva, que expressa um ponto de vista sem envolver o interlocutor diretamente. Os dizeres expressos nos editoriais 1 e 2, da edição 79, ancoram-se nos modos enunciativo-alocutivo e narrativo, pois encadeiam enunciados que retomam as histórias de vida de diretores da empresa, propondo o engajamento para o 
sucesso da organização. Observam-se tais questões nos seguintes enunciados: "comemorar os 30 anos da Hera nos faz refletir sobre o ambiente que, em 1982, eu e Beltrano, fundamos a empresa" (EDIÇÃO 79a) e "há 27 anos lembro de estar em São Paulo, com minha família. Meu filho T2 havia recém-nascido e eu levantava todos os dias muito cedo e ia tomar café" (EDIÇÃO 79b).

O excerto "aqui, contamos com profissionais qualificados que dedicam o seu tempo na criação de soluções inovadoras com tecnologia de ponta", divulgado no editorial da edição 80, exemplifica a fundamentação adotada pelo EUc para construção dos editoriais: 1) na função alocutiva do modo enunciativo, para apresentar as prescrições ao ambiente laboral; e, principalmente, 2) no modo argumentativo, pois cada asserção é justificada a fim de persuadir o interlocutor a seguir as normas postas. Enunciados das edições 81 - "assim, também podemos manter nosso constante aprimoramento de gestão administrativa" - e edição 82 - "a exigência sobre aquilo que fazemos será cada vez mais alta e encaramos isto com empolgação" - sustentam, também, esse apontamento analítico.

As estratégias discursivas utilizadas nos editoriais do jornal refletem o uso das visadas comunicativas na tensão entre fazer-saber (visada de informação) e fazer-sentir (visada de captação). O "jogo consiste em navegar entre esses dois polos ao sabor de sua ideologia e da natureza dos acontecimentos" (CHARAUDEAU, 2012, p. 93). Mesmo que seja preponderante o uso das visadas de informação e de prescrição à composição dos discursos, diante dos elementos ideológicos e dos orientadores de conduta, a visada 
de captação tem, também, destaque. Exemplifica-se tal afirmação com base nos enunciados: "graças ao trabalho de muitas pessoas que dedicaram entusiasmo, coragem e disposição", na edição 77, "isso significa dizer que fazemos, orgulhosamente, parte de um terço desta história de seis décadas", na edição 82, e, na edição 83: "não é bom saber que ajudamos na diversão de um dos parques temáticos mais modernos da América do Sul?".

Combinado à predominância das ações determinadas pelas visadas, fazer-saber para dever-saber / dever-fazer, das informações e prescrições referentes à finalidade do ato comunicativo, outros aspectos do contrato de comunicação (CHARAUDEAU, 2012) contribuem à percepção do contexto organizacional (cultura). O espaço de relação revela o tom prescritivo e informativo e o caráter introvertido e exigente do enunciador, que tem associado à sua identidade o interesse no estabelecimento de uma linearidade discursiva, desconsiderando a opinião dos trabalhadores e impondo-lhes comportamentos considerados adequados para o exercício da atividade. Ilustra-se esse aspecto com um trecho presente no editorial da edição 78: "hoje é necessário colocar nossa inteligência dentro da máquina e a máquina dentro da indústria. É isso que estamos fazendo na Unidade de Painéis"; "[os produtos] são recheados de conhecimento"; "[...] engarrafar de forma metódica conhecimento em produtos".

A abordagem e a justificativa de tomada da fala, diante do espaço de locução, reforçam o interesse em orientar a ação, seja por meio de asserções diretas e impositivas, seja pelo uso de narrativas de vida que, além de servir como modelo de condu- 
ta, também tende a envolver emocionalmente os interlocutores. Justifica-se essa asserção com base no fragmento disponível no editorial da edição 79b: "Saía bem cedo num Gol branco a visitar clientes de forma frenética apresentando as vantagens do nosso primeiro AL-1000. Ali eu cultivava o conhecimento de vendas e o de conhecer pessoas". Exaltam-se os seguintes comportamentos, os quais, supõe-se, são exemplares aos interlocutores: sair bem cedo, visitar clientes de forma frenética e cultivar conhecimento. Neste mesmo editorial, identifica-se a verticalização de posições entre líderes (para usar o termo presente nos editoriais dos jornais de empresa) e liderados. "Definidas nossas metas e ações a serem atingidas para cada time, que as lideranças destes levem em conta que para atingirmos isto [...]".

A leitura dos editoriais evidencia o interesse em estabelecer uma hegemonia de valores e perspectivas ante a imposição dos saberes constituídos (SCHWARTZ; DURRIVE, 2007). Argumenta-se constantemente a favor dos comportamentos que são lou devem) ser seguidos. No editorial da edição 79b, o enunciado "por outro lado nós mesmos devemos nos comportar de forma a demonstrar nosso estado de espírito mais importante: estar de bem com a vida" prescreve uma ação: estar de bem com a vida. $\mathrm{Na}$ sequência, afirma: "estar de bem com a vida que significa o sorriso fácil, o elogio frequente, o alerta jocoso e um espírito otimista". Esclarece-se, então, o que se entende como estado mais importante e quais são as atitudes esperadas dos trabalhadores. Tal expressão dá-se pelo uso de mais prescrições, ficando evidente a recusa da subjetividade do sujeito como interpretante de uma prescrição vaga como "estar de bem 
com a vida". As prescrições são postas e justificadas, a fim de evitar questionamentos, sem reconhecer no cotidiano práticas que são transformadas diante dos eventos inesperados e do investimento de saberes dos trabalhadores (SCHWARTZ; DURRIVE, 2007).

O volume de prescrições expressa a clareza com a qual a organização pensa tratar seus processos, enquanto as lideranças têm como função a disseminação, fiscalização e cumprimento das normas. Essa característica discursiva da empresa Hera exemplifica o que Schwartz e Durrive (2007, p. 197) mencionam acerca da redução da atividade "a um ponto em que se teve a tendência a unicamente encarar o uso de si pelos outros". Porém, como esses autores complementam, "jamais ninguém poderá encerrá-la em uma moldura, por mais sedutora que ela seja" (SCHWARTZ; DURRIVE, 2007, p. 200). Nesse sentido, os editoriais podem ser indicados como elemento revelador de uma problemática que precisa ser avaliada pela organização, já que almeja "ampliar nosso potencial de empresa e nos fazer ser cada vez mais a empresa que evolui dia a dia na automação industrial" (Edição 79b).

No corpus selecionado é possível identificar, ainda, a exaltação de algumas áreas em relação a outras. Entre os trabalhadores do P\&D, por exemplo, reconhecem-se comportamentos como trabalhar duro, estudar, renovar os produtos etc. Exemplifica-se com excertos das edições 80 "[...] que continua a ser estudada e renovada em nosso processo de Pesquisa \& Desenvolvimento" e 81 "tudo isso não seria possível sem o trabalho duro de nosso P\&D". Aos trabalhadores da fábrica são incentivadas outras condutas, não expressas pelos editoriais, o que leva a crer que são 
diferentes das declaradas. É iminente a possibilidade de conflito entre os trabalhadores das duas áreas. A atividade de uns tende a ser percebida como superior à dos outros. Desse modo, o foco na atividade em si é perdido em razão das diferenças, quando ambas as áreas são fundamentais para que um dos objetivos principais da empresa possa ser atendido: "vencer e satisfazer o cliente" (EDIÇÃO 83). Contrapondo sua própria orientação, a organização cria uma hierarquia entre as áreas, sendo sua relevância aos negócios posta em uma balança, como forças iguais. Nesse caso, conflitos negativos tendem a ser instaurados, visto que pautados por questões particulares entre fulano e beltrano, que refletem as escalas de importância expressas pela organização.

Compreende-se que as prescrições atuam na criação de mecanismos para orientar a interpretar os sentidos (DAFT; WEICK, 1984). Uma vez que os significados que se deseja comunicar são expostos e registrados nos jornais, a organização determina o que cobrará de seus trabalhadores que, em contrapartida, sabem quais padrões devem seguir se quiserem pertencer àquele ambiente. "Assim como a seleção brasileira se prepara para o mundial, a Hera trabalha para a copa da tecnologia de automação. Ao longo dos anos, treinamos diariamente para criar produtos que surpreendam. Tudo para vencer a partida e satisfazer nossos clientes" (EDIÇÃO 83). A correlação estabelecida entre o evento esportivo e o cotidiano da empresa salienta o ritmo que se almeja e aciona implícitos acerca do modus operandi pretendido, o que exemplifica essa questão, conforme referem Oliveira e Paula (2008). Para essas autoras, por vezes as organizações são ordenadoras de sentidos 
e expressam as ordens por meio de manuais ou, no caso deste estudo, em jornais da empresa. "Quando colocado em ação, o código de ética [ou os jornais, com sua vasta normalização] não só regula e ordena as relações, como também prevê a possibilidade de surgirem outras versões e novos sentidos" (OLIVEIRA; PAULA, 2008, p. 104).

Aspectos como esses levam à sugestão da determinação de perfis profissionais adequados ou inadequados, ponto de vista considerado na definição da identidade projetada (EUe>TUd) do trabalhador como destinatário ideal desse ato de comunicação. O destinatário é percebido como imerso nos objetivos de negócio da Hera, seja por seu prévio interesse, seja por imposição da empresa. Só permanece quem se ajusta e busca produzir dentro dos parâmetros determinados. Pode-se supor que a classe trabalhadora é classificada em dois grupos: aqueles que pensam para a organização e aqueles que executam o que foi pensado. É provável o julgamento de que os trabalhadores da fábrica não tenham interesse no conteúdo produzido para o jornal, logo, não é necessário comunicar-se com eles por esse meio. Essa percepção ancora-se na indicação de que o fazer de uns é reconhecido, enquanto a menção ao trabalho dos outros se relaciona à máquina produzida. Em ambos os casos, interessa apenas o resultado da ação, não a atividade em si.

\section{Considerações finais}

A opção por observar interações no contexto sociocultural produzido pelo trabalho nas organizações a partir de discursos prescritivos pode parecer reducionista ou avessa a um primeiro olhar. Visto mais 
de perto, percebe-se que o fenômeno linguageiro, vinculado a concepções que evidenciam questões subjetivas dos sujeitos, permite a realização de apontamentos para avaliar os estímulos produzidos e sua posterior comparação às manifestações informais no ambiente laboral. Defende-se que a análise teórico-ergo-discursiva de discursos normalizadores pode identificar elementos implícitos da cultura e do contexto que permeia o trabalho, e que dificilmente seriam apontados pelos trabalhadores caso fossem questionados.

Quanto ao caso específico em análise, pode-se perceber que os editoriais do jornal da empresa Hera, estruturados em grande parte por visadas de informação, tornando conhecidas as normas, também se valem das estratégias de captação, do uso de argumentos que persuadam o interlocutor e produzam seu engajamento à tematização. Sintetizam-se alguns sentidos produzidos e que implicam os processos interacionais e a ação renormalizadora dos sujeitos no trabalho: cerceamento e modalização da atividade com a determinação de quais comportamentos são esperados. É uma tentativa de tornar hegemônico o discurso prescritivo da organização pela imposição de saberes constituídos, abrindo a oportunidade de renormalizar apenas os trabalhadores do P\&D, além de criar mecanismos para ordenar a interpretação dos sentidos que possam circular no ambiente laboral. Quanto ao destinatário idealizado (TUd) pelo enunciador (EUe) e expresso pelo emissor (EUC), pode ser caracterizado pela passividade quanto ao uso de si pelo outro, uma vez que se prevê um alinhamento aos comportamentos valorizados e observado pelas lideranças. 
Desse modo, destaca-se dos aspectos apresentados na análise a consistência da materialidade selecionada na investigação: os discursos prescritivos. No caso específico dos editoriais, sabe-se que se referem a um gênero discursivo permeado por intencionalidades acerca do exercício laboral. Neste caso, percebe-se o propósito central de neutralizar a atividade dos sujeitos, por meio da ilusória noção de controle das práticas laborais e pela fixação de um volume excessivo de normas. A Hera tende a produzir sentidos contraproducentes à sua cadeia produtiva, o que parece desencorajar a inovação na produção de produtos, serviços e processos além de suprimir o aprimoramento pessoal e criativo dos trabalhadores.

\section{Referências}

BAKHTIN, M. (V. N. Volochínov). Marxismo e filosofia da linguagem. São Paulo: Hucitec, 2014.

BENVENISTE, É. Problemas de linguística geral I. São Paulo: Edusp, 2008.

ChARAUDEAU, P. Discurso das mídias. São Paulo: Contexto, 2012.

CHARAUDEAU, P. Linguagem e discurso: modos de organização. São Paulo: Contexto, 2010.

DAFT, R. L.; WEICK, K. E. Toward a model of organizations as interpretation systems. The Academy of Management Review, v. 9, n. 2, p. 284-291, abr. 1984.

HERA. Editorial do Jornal da Empresa, Edição 77, março de 2012.

HERA. Editorial do Jornal da Empresa, Edição 78, agosto de 2012.

HERA. Editorial 1 do Jornal da Empresa, Edição 79a, outubro de 2012.

HERA. Editorial 2 do Jornal da Empresa, Edição 79b, outubro de 2012. 
HERA. Editorial do Jornal da Empresa, Edição 80, maio, 2013.

HERA. Editorial do Jornal da Empresa, Edição 81, agosto de 2013.

HERA. Editorial do Jornal da Empresa, Edição 82, novembro de 2013.

HERA. Editorial do Jornal da Empresa, Edição 83, abril de 2014.

OLIVEIRA, I. de L.; PAULA, C. F. C. de. Comunicação no contexto das organizações: produtora ou ordenadora de sentidos. In: OLIVEIRA, I. de L.; SOARES, A. T. N. (Orgs.). Interfaces e tendências da comunicação no contexto das organizações. São Caetano do Sul: Difusão, 2008. p. 91-108.

PAULIUKONIS, M. A. L.; GOUVÊA, L. H. M. Texto como discurso: uma visão semiolinguística. Desenredo - Revista do Programa de PósGraduação em Letras da Universidade de Passo Fundo, v. 8, n. 1, p. 49-70, 2012.

SARAIVA, L. A. S.; CARRIERI, A. de P. Dinâmica simbólica nas organizações. In: MARCHIORI, M. (Org.). Comunicação e organização: reflexões, processos e práticas. São Caetano do Sul: Difusão, 2010. p. 209-222.

SCHWARTZ, Y. Circulações, dramáticas, eficácias da atividade industriosa. Revista Trabalho, Educação e Saúde, v. 2, n. 1, p. 33-55, 2004. SCHWARTZ, Y. Motivações do conceito de corpo-si. Revista Letras de Hoje, Porto Alegre, v. 49, n. 3, p. 259-274, jul.-set. 2014.

SCHWARTZ, Y; DURRIVE, L. (Orgs.). Trabalho e ergologia: conversas sobre a atividade humana. Niterói: Eduff, 2007.

SOUZA-E-SILVA, M. C. P. A dimensão linguageira em situações de trabalho. In: SOUZA-E-SILVA, M. C. P.; FAÏTA, D. (Orgs.). Linguagem e trabalho: construção de objetos de análise no Brasil e na França. São Paulo: Cortez, 2002. p. 61-76.

TRINQUET, P. Trabalho e educação: o método ergológico. Revista Histedbr On-Line, Campinas, número especial, p. 93-113, ago. 2010. 


\section{ERnani Cesar de Freitas \\ Gislene Feiten Haubrich}

\section{DAdOS dOS AUTORES}

\section{Ernani Cesar de Freitas}

Doutor em letras (PUCRS), com pós-Doutorado em Linguística Aplicada e Estudos da Linguagem (PUC-SP/LAEL).

Docente do PPG em Processos e Manifestações Culturais na Universidade Feevale.

Lattes; http://lattes. cnpq.br/9653110286244674

\section{Gislene Feiten Haubrich}

Doutoranda e mestre em Processos e Manifestações Culturais pela Universidade Feevale.

Lattes: http://lattes.cnpq.br/9771390371218321 